\title{
Using photography to enhance GP trainees' reflective practice and professional development
}

\author{
Rutherford, ${ }^{1}$ Emer Forde, ${ }^{2}$ Jacqueline Priego-Hernandez, ${ }_{1}^{3}$ Aurelia Butcher, ${ }^{2}$ \\ Clare Wedderburn ${ }^{2}$
}

'Department of Corporate and Marketing Communication, Bournemouth University, Faculty of Media \& Communication, Poole, UK

${ }^{2} \mathrm{GP}$ Centre, Bournemouth University, Poole, UK ${ }^{3}$ School of Social, Historical and Literary Studies, University of Portsmouth, Portsmouth, UK

\section{Correspondence to} Dr Emer Forde, GP Centre, Bournemouth University, Poole BH12 5BB, UK;

eforde@bournemouth.ac.uk

Accepted 29 November 2017

Check for updates

To cite: Rutherford, Forde $\mathrm{E}$, Priego-Hernandez J, et al. Med Humanit Epub ahead of print: [please include Day Month Year]. doi:10.1136/ medhum-2017-011203

\section{ABSTRACT}

The capacity and the commitment to reflect are integral to the practice of medicine and are core components of most general practitioners (GP) training programmes. Teaching through the humanities is a growing area within medical education, but one which is often considered a voluntary 'add-on' for the interested doctor. This article describes an evaluation of a highly innovative pedagogical project which used photography as a means to enhance GP trainees' reflective capacity, selfawareness and professional development. Photography was used as a tool to develop GP trainees' skills in recognising and articulating the attitudes, feelings and values that might impact on their clinical work and to enhance their confidence in their ability to deal with these concerns/issues. We submit that photography is uniquely well suited for facilitating insight and selfreflection because it provides the ability to record 'at the touch of a button' those scenes and images to which our attention is intuitively drawn without the need for-or the interference of - conscious decisions. This allows us the opportunity to reflect later on the reasons for our intuitive attraction to these scenes. These photography workshops were a compulsory part of the GP training programme and, despite the participants' traditional scientific backgrounds, the results clearly demonstrate the willingness of participants to accept-even embracethe use of art as a tool for learning. The GP trainees who took part in this project acknowledged it to be beneficial for both their personal and professional development.

\section{INTRODUCTION}

Reflective capacity is the ability to analyse the basis of one's knowledge, decision-making and behaviour in order to promote learning and, if necessary, to make changes to future behaviour. Reflection can foster professionalism, empathy and attitudinal changes. Enhancing self-awareness can also illuminate what we value and what causes us stress and, consequently, lead to increased resilience. ${ }^{1}$ For these reasons, the General Medical Council requires all doctors to regularly reflect on their performance and professional values, and reflection forms an essential component of revalidation for all qualified doctors in the UK.

The Royal College of General Practitioners (RCGP) mandates GP trainees in the UK to maintain an e-portfolio of reflective writing which forms a significant part of their assessment for qualification. Reflective practice is therefore integral to fitness to practice and 'maintaining an ethical approach' in the RCGP training curriculum because:
There will be cultural (including religious) differences between you and many of your patients. Your own values, attitudes and feelings are important determinants of how you practice medicine. This is especially true in general practice where you as a doctor will be involved in a one-to-one and continuing relationship with your patient, not merely as a medical provider.

As a GP you should aim at understanding and learning to use your own attitudes, strengths and weaknesses, values and beliefs in a partnership with your individual patients. This requires a reflective approach and the development of insight and an awareness of self. Being honest and realistic about your own abilities, strengths, weaknesses and priorities will help you in dealing with your patients and problems; the lack of self awareness will make your job as a GP very difficult. ${ }^{2}$

Karkabi, Wald and Castel suggested that reflective practice is not an innate skill and medical training schemes need to both promote the value of reflection and provide practical instruction that will enable the development of the capacity to reflect. ${ }^{3}$ The humanities offer an innovative pedagogical tool for this, and various approaches have been used including creative writing, ${ }^{4}$ use of comics, ${ }^{5}$ film, ${ }^{6}$ theatre $^{7}$ and paintings. ${ }^{389}$ For example, Karkabi and Castel presented paintings to medical students, who were then asked to write narratives based on the paintings and their clinical experiences. These students reported that art was an innovative and helpful way to enhance their reflective capacity and that writing narratives encouraged them to reflect on their emotions and behaviour. The workshops helped the medical students identify, and discuss, their emotions of anxiety, fear of making mistakes, lack of confidence, helplessness and frustration. These can be difficult to discuss openly in more traditional teaching sessions. A recent literature review of narrative-based education highlighted the importance of small group discussions and the benefits in communication skills, empathy, personal and professional development, and job satisfaction. ${ }^{10}$ However, more research is needed to show the acceptability, and benefits, of arts-based medical education to students and qualified doctors. ${ }^{11}{ }^{12} \mathrm{~A}$ recent UK All-Party Parliamentary Group Inquiry Report highlighted the importance and potential for art to enhance health, including the health and well-being of medical professionals. ${ }^{13}$ A key recommendation was that the education of all healthcare professionals should include dedicated arts-based modules.

To date, there has been very little research on the use of photographic arts in medical education. A 
small number of studies have shown that it can foster reflective practice and empathy ${ }^{14-16}$ However, to the best of our knowledge, there have been no studies investigating whether doctors can develop their reflective practice and professional development through reflecting on their own photographs.

This article describes an innovative pedagogical project which used photography as a tool to help GP trainees to recognise, explore and articulate the ways in which the issues and challenges with which they are confronted might affect their work as doctors. It was hoped that these photography workshops would create a safe space, away from the usual demands of the medical world, where GP trainees could share their stories. The workshops were physically away from their clinical environments, and the use of photography provided an educational atmosphere far removed from their usual medical training.

\section{WHY PHOTOGRAPHY?}

Most of us make photographs. In addition to our photographs of friends and family, holidays and special events, many of us also photograph things just because we liked the way something looked-often without knowing why our attention was drawn to a particular scene. For example, we might photograph two children playing in a park, or an abandoned house or a broken bicycle lying in the grass-but we do not know those children, or the people who lived in that house and that is not our bicycle. When our attention is intuitively drawn to a scene or event 'out there' with which we have no personal or conscious connection, this may be an indication of a 'meaningful resonance' for us: an intuitively recognised symbol for some issue or concern below the horizon of our conscious awareness and to which, with a 'subliminal tap on the shoulder', our subconscious is now attempting to bring to our attention. ${ }^{17}$

While all forms of creative expression offer the opportunity for increased self-awareness, the medium of photography offers a significant advantage in accessing the 'subconscious' mind. By giving us the ability to record, at the touch of a button, those scenes to which our attention is intuitively drawn, the camera gives us the means to record what may be meaningful metaphors without the need for-and, more importantly, without the interference of-conscious decisions. ${ }^{17}$

According to Sacks, ${ }^{18}$ 'the brain's record of everything [is] iconic'. Do we, for example, picture our life as 'a path to be explored', 'a journey to be enjoyed', 'a ladder to be climbed' or as 'a competitive struggle against hostile forces to be won'? The way in which we 'mentally picture' (or 'imagine' the root of which is 'image') our life informs our goals and the 'rules' we must follow in order to achieve it. For example, how do we mentally picture 'success'? Is it the accumulation of wealth and material possessions, the achievement of personal or professional status, the attainment of power, the feeling that we did something 'meaningful' with our lives and impacted positively on the world around us or the rewards to be found in being worthy of the love and respect of those around us?

Philosophers and psychologists have long debated how we find meaning in life. For example, to be able to make appropriate decisions in pursuit of genuinely fulfilling goals, Jung ${ }^{19}$ advised that it is necessary to examine the way in which we 'imagine' or 'mentally picture' our goals-because these determine the 'evidence' we pursue as proof - and what we pursue will shape the life we will lead and the shape of the world we will leave behind.

Through careful and honest reflection on our associations with both what we have intuitively 'chosen' to photograph (the individual elements included in our photographs) and the way we have arranged or composed these elements within the frame, our photographs sometimes offer us glimpses of our personal iconography: allegorical depictions of the private myths through which we define our Selves, plot our course and live our lives.

While the scenes and images of the world 'out there' provide the raw material of our photographs, their real subject, what our photographs are actually 'about', is sometimes a description of (and a commentary on) the interior landscape of our needs, hopes, longings and fears. For example, in the scene of children playing together, we may subconsciously have recognised a metaphor for the acceptance by others we feel we lack, the sister we miss or the desire to have more time for fun and joy in our lives. An abandoned bicycle may remind us of a father who (we felt) was never there, or the end of a journey.

To me, photography is an art of observation. It's about finding something interesting in an ordinary place. I've found it has little to do with the things you see and everything to do with the way you see them. Elliott Erwitt. ${ }^{20}$

\section{DESCRIPTION OF THE PROJECT}

In this highly innovative approach to medical education, GP trainees worked with a photographic artist (Rutherford) to help develop their reflective capacity by identifying, reflecting on and decoding the narratives embedded in their 'snapshots'. Our initial objective was to assess whether, with their very traditional scientific backgrounds and empirical way of thinking, doctors would find photography acceptable as an educational tool. Would doctors engage with the photography project and find it useful? What themes (if any) would dominate GP trainees' photographs?

Eight GP trainees who had completed 18 months of hospital rotations and were starting the final 18 months of their training in GP surgeries were invited to participate in two workshops, each lasting 3 hours. There were seven females and one male. No other demographic data were recorded. Importantly, participants were not self-selecting and the workshops formed a compulsory part of their GP education programme.

\section{Workshop 1}

During the first workshop, the GP trainees were introduced to the idea that reflecting on what we photograph and the way in which we photograph it can provide us with the means to enhance self-awareness. The GP trainees were encouraged to consider the possibility that by exploring our associations with the scenes, events and 'moments' we are intuitively drawn to record, we can illuminate salient issues in our personal and professional lives. They were offered the metaphor of a flashbulb briefly illuminating a dark street and the goings-on in the shadows only revealed later when the resulting image is produced. It was suggested to the GP trainees that their photographs can sometimes provide picture postcards of the emotional landscapes they inhabit. To assist and encourage the GP trainees in this process, they were asked to bring two photographs they had made previously, and which still evoked an emotional response, to the first workshop. This collection of photographs was presented anonymously for a group discussion on the 'stories' these photographs appeared to tell, the emotions they evoked and why these images might have been salient for the photographer. The purpose of this exercise was to encourage the GP trainees to begin to look at the scenes and events within photographs as metaphors, to identify their own emotional responses to the photographs, and to consider how the images might allegorically depict the emotions 


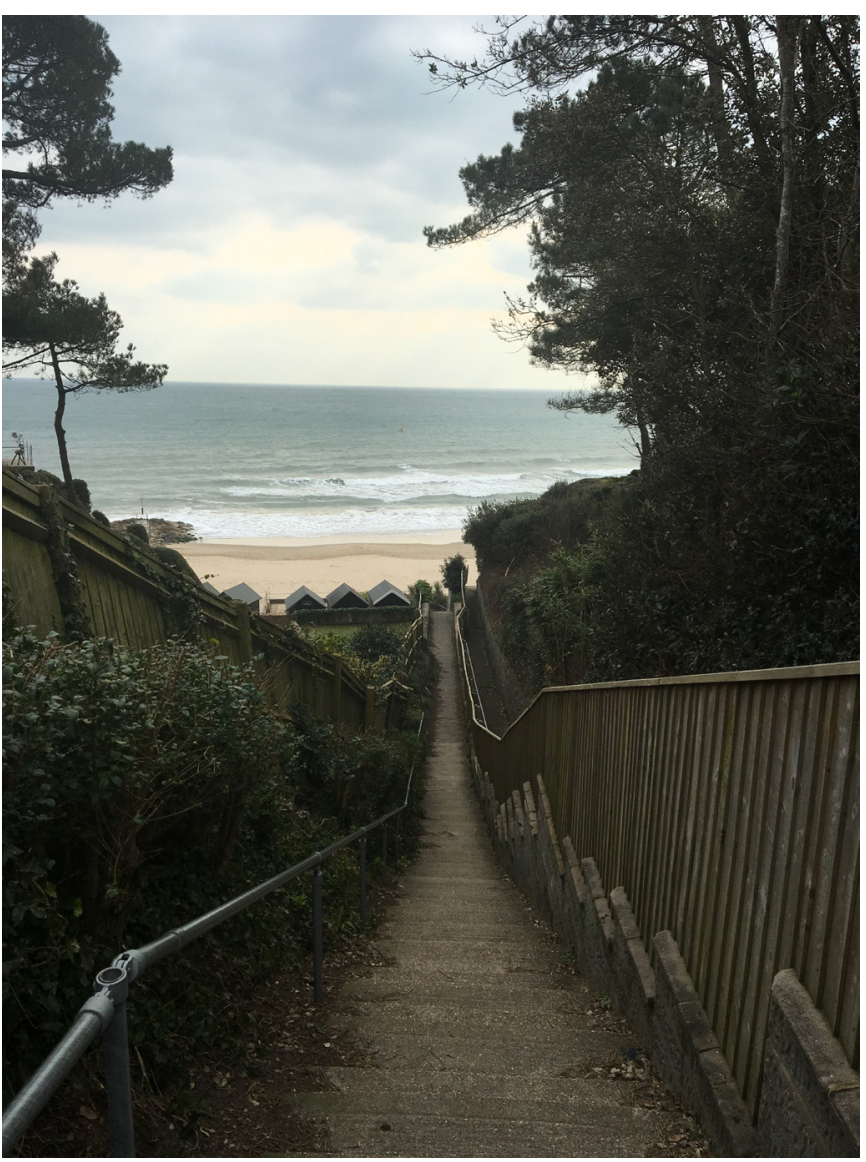

Figure 1 'The path is not a particularly pleasant place but it is worth the short journey as the photographer will end up somewhere lovely. I think the path represents the final part of my training and the beach is the final goal of being a GP.'

and/or associations experienced by another person (the photographer of each picture).

The GP trainees were then asked to carry a camera with them at all times (eg, on their smart phones) and to be prepared to record those scenes and events to which they felt an intuitive attraction. They were asked not to think about how to compose their photographs, not to try to make it look 'good' or 'pretty', but to allow their intuition to determine both the arrangements of the elements within the frame and the moment at which it 'felt right' to push the button. The GP trainees were given written instructions to photograph scenes and images that caught their attention. For example:

1. scenes or images that make you feel happy when you look at them

2. scenes or images that make you feel angry

3. scenes or images that make you feel sad

4. scenes or images that frighten you

5. scenes or images that seem to be an 'environmental self-portrait'

6. scenes or images that describe your relationship with others

7. scenes or images that remind you of the relationships within your family

8. scenes or images that describe what your life is like

9. scenes or images that describe or represent something which you feel is missing from your life

10. scenes or images that describe or represent the life you would like to have in the future

11. scenes or images that seem to describe or represent some choice that is necessary
12. scenes or images that seem to describe the future (such as 'the way ahead' is bright, or that 'the way ahead' will be full of challenges or difficulties).

The GP trainees were specifically asked not to look for scenes or events which illustrated an idea (eg, not to photograph an elderly person sitting on a bench as a depiction of 'loneliness'). Instead, they were encouraged to try to remain alert to scenes that attracted their attention and provoked an intuitive response.

\section{Workshop 2}

Following the first workshop, the GP trainees had 4 weeks in which to produce a series of photographs. At the end of the 4 weeks, they were asked to look through their photographs 'absent mindedly' and select four or five images to which they responded with an 'emotional tap on the shoulder' (ie, those images to which they found their attention repeatedly drawn, and/or those they looked at longer). These photographs were anonymously presented to the group, who discussed the possible significance of the various elements and their juxtapositions within the compositions. Participants did not identify themselves when their photographs were discussed. They listened to the group's initial responses to the images and the group's reflections of what might have been important to the photographer.

\section{Reflective writing}

Following these two workshops, the GP trainees were asked to make a final selection of four or five photographs from the set they had taken over the preceding weeks. They were asked to write 500-1000 words of reflective prose describing the significance and personal insights they recognised within each image and, more generally, what value (if any) they believed they had gained from the project. Following the submission of their texts and accompanying photographs, each GP trainee was given written feedback from two GP educators (EF and $\mathrm{AB}$ ) and the photographic artist (Rutherford).

\section{Guidance given to the GP trainees in interpreting the photographs}

To uncover the meaning or significance of the messages in the resulting photographs, the GP trainees were encouraged to look for clues in both the individual elements of the photographs and the 'story' it seemed to tell through the way in which the individual elements related to one another (Gestalt). They were asked to identify which of the elements seem to be the main characters in the 'story', as well as the place(s) where their eyes naturally came to rest-for it is there they were likely to find the most significant element(s) of the picture. It was explained that these elements could either be concrete (eg, a tree, path or shadow) or implied in the relationships between the different objects in the scene (eg, the fact that everyone is looking in a particular direction). The GP trainees were also asked to notice whether there were any elements conspicuous by their absence and to consider what was going on in their lives at the time that each photograph was made. It was suggested that, while it is possible to misinterpret a single image, it may be possible to identify valuable clues in the similarities and/or recurring themes within their sets of photographs.

\section{Guidance to the GPs in preparing their reflective texts}

The GP trainees were asked to reflect on the following questions:

- What is the 'story' in this photograph? What is going on? What is happening (or what has just happened, or is about to happen) to the 'characters' in this play?

- What is the issue or aspect of your life or personality to which the photograph seems to refer? 


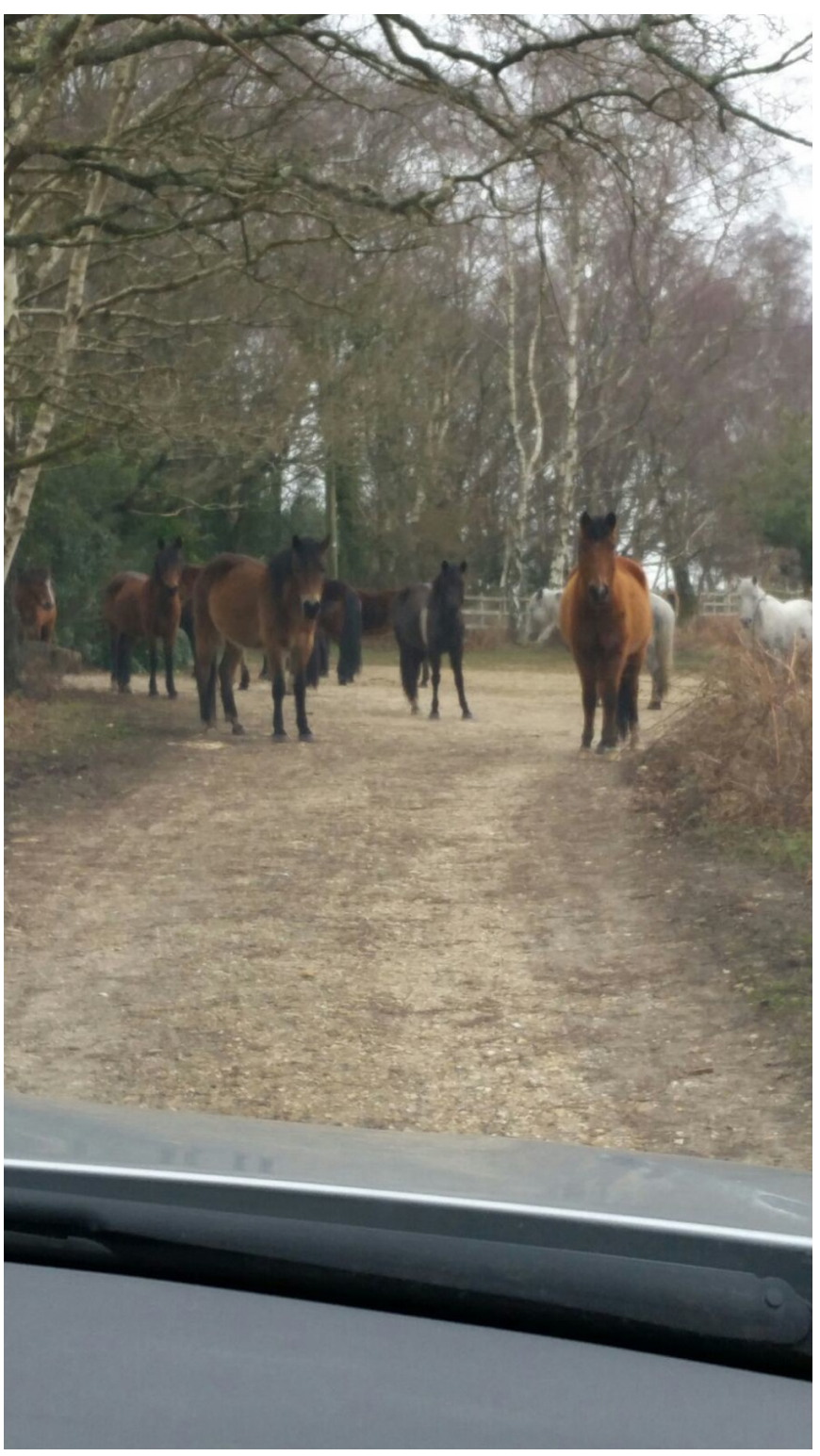

Figure 2 'This photo shows a pathway but this time it [is] blocked by the horses. They are all staring at the driver in the car and seem to be actively preventing them from proceeding. This photo makes me feel uneasy and almost trapped like I can not move forward. I am not sure how I am going to get through or what is going to happen If I get closer to them. I think I am probably drawn towards this photo in particular as I am currently trying to get through the next obstacle in my training, my Applied Knowledge Test exam and feel currently like that is a challenging hurdle.'

- What are the visual symbols in which you identified the 'story' being told? Bear in mind that the clue to the 'story' is often to be found in the relationships implied between the physical objects.

- What is the meaning of the photograph to you? What do you think your 'subconscious' is trying to tell you?

\section{Qualitative analysis of photographs and written reflections}

This work started as an innovative pedagogical development in our GP training scheme and the power of photographs to develop reflective capacity became clear as the project unfolded. Consequently, on completion of the workshops, when

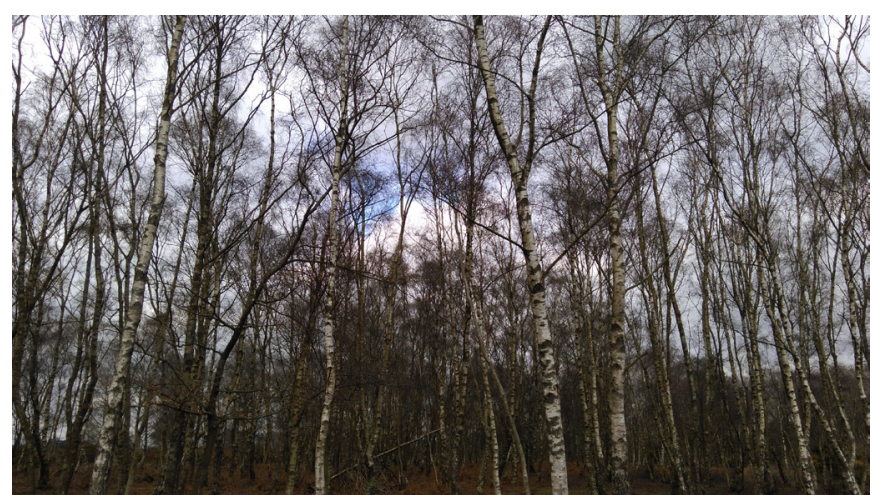

Figure 3 'There is an obstacle and no clear path to the 'other side'. They both show a 'here' and 'there'. The 'there' symbolises where I want to end up, where there is light and open space, which to me represent possibility, freedom and fulfilment. I think I create the obstacle from my own surroundings out of negative thoughts and self-doubt. But the majority of the frame is ordered and bright, making it feel hopeful. I think this is my subconscious suggesting that my doubts about my ability are groundless.'

participants had a full understanding of what the workshops involved, had participated in group discussions of their photographs and received written feedback on their reflections, we sought informed written consent to use their photographs and written work to disseminate the educational approach and for research purposes. It was important to obtain informed consent at this stage so participants had the opportunity to review the very personal nature of some of their reflections. Seven of the eight GP trainees (six females, one male) gave written consent for their photographs and reflective prose to be analysed and disseminated for research purposes. One GP trainee did not give consent, and her photographs and text were not included in this analysis.

A qualitative researcher (JP-H), who had not been involved in the workshops, analysed the photographs and reflective text to provide an analysis of the dominant themes. Thirty-one photographs and seven reflective texts were systematised in the software MAXQDA (Verbi Software, 2017). Standard thematic analysis was performed, focusing first on inducing descriptive categories from the data by looking at photographs and texts separately. This produced a coding frame for visual and textual data sources. ${ }^{21} \mathrm{Next}$, the two coding frames were compared and consolidated into the most salient categories, based on the number of coded segments in the texts and photographs. In refining the coding frame, visual and linguistic features of the software were used to explore the data, such as lemmatised word count and coding. For example, 'think', 'feel', 'path' and 'contrast' were words of interest due to their frequent presence in the texts and their distribution across different participants' reflections. An auditable track of coding decisions including interpretive memos was kept throughout the analysis.

The two most dominant themes identified were GP trainees' feelings about 'being on a journey' and their 'need for balance'.

\section{Being on a journey}

GP trainees contrasted their professional journey (their training) towards a desired destination (being a qualified GP). Their journeys were frequently described as one with obstacles and a necessary route that must be undertaken in order to reach a desired academic, social and professional place (see figure 1). GP trainees reflected on the meaning of the obstacles and complications 


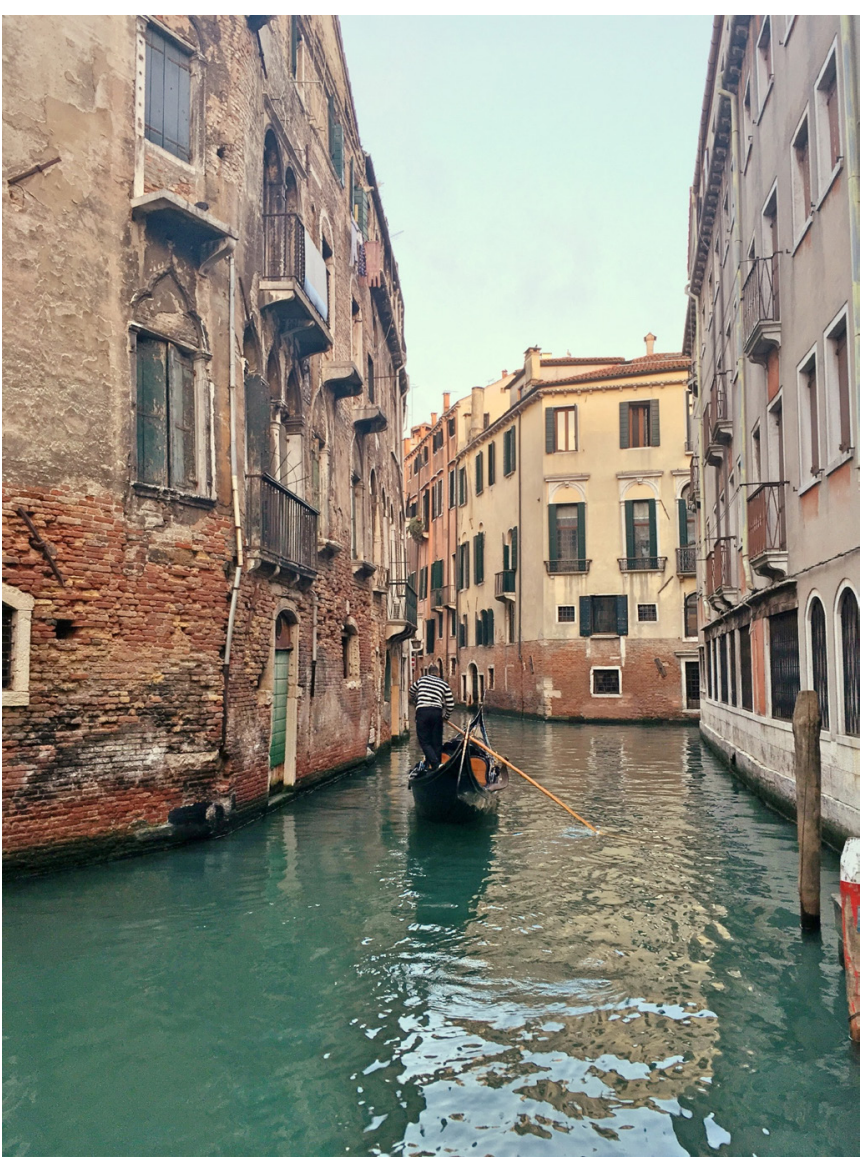

Figure 4 'I was drawn to this photo because of the contrast between the worn-out buildings on the left and the newer on the right...I wonder if I am drawn to this because his path is unclear-it looks like there may be two paths... Perhaps I feel trapped on a boat, on a path unknown, unable to just step off and take a breather. It certainly feels that since I headed to university to study medicine, there have been times when I have thought about what it would feel like to do something else or travel the world, but felt unable to diverge from the path I was on, or step off the boat.'

encountered on their journeys, how these difficulties originated and their strategies for tackling them (see figures 2 and 3). Pathways and roads were the most coded for visual elements in the photographs. There were frequently intersections, junctions and stops where the future path was obstructed or unclear. Along this symbolic way there was always the potential to stop, to contemplate their destinations, to reconsider and, where necessary, to adjust their routes. See, for example, figure 4 and the associated reflection.

\section{The need for balance}

The other dominant theme was a need for balance. GP trainees' photographs and reflective prose suggested a need for coherence and equilibrium in their lives, and their perception that they often face competing demands, clashing desires and contrasting roles in the professional, social, family and community spheres. The following two quotes illustrate this need for balance as feelings of contrast and dualism in their lives (emphasis added by coder).

Contrast features heavily in the photographs I have taken. It presents itself as man versus nature, light versus dark and earth versus sky...

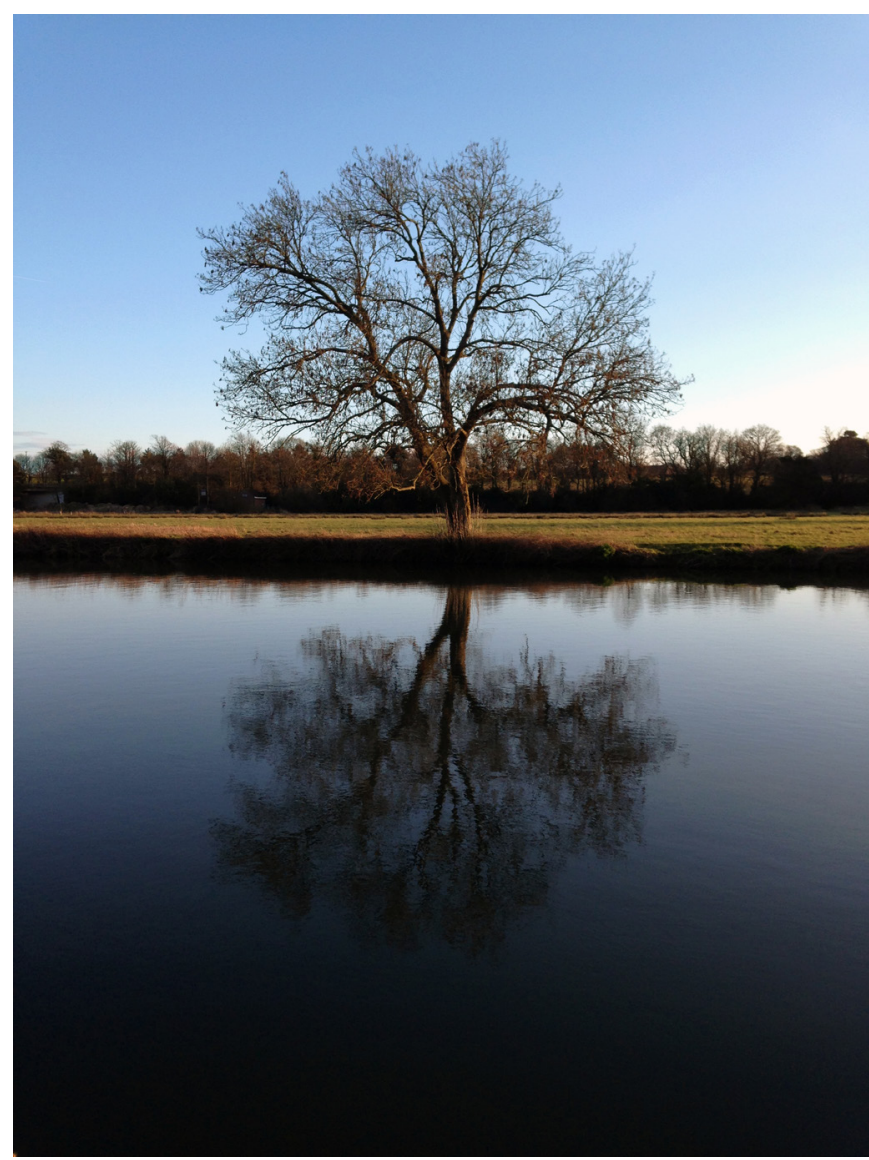

Figure 5 'The tree is looking at its own reflection as a form of introspection ... I think this represents that I value time to myself, on my own ... away from the crowd.'

There is a lot of contrast and dualism in the photographs. Perhaps this reflects the contrast I see within myself or the balance between contrasting demands placed on me by my work and training and my personal life. Particularly the first three photographs have elements of life and death, this is something that as a doctor, I find myself confronting on a regular basis. It is something that I find frightening but also something I feel privileged to experience.

Balance and contrast was applicable to many other domains that also appeared in the photographs. For example, one GP trainee reflected on balancing professional and personal priorities and the personal sacrifice she had made in leaving loved ones 'behind' in the pursuit of her career. Others reflected on the need for balance between being in a profession in which there is a constant contact with people and their need for, and enjoyment of, moments of solitude (see figure 5).

\section{Did doctors value photography as a means to enhance their professional development?}

GP trainees were asked to rate their responses to the following questions on a nine-point Likert scale from 1 (not at all) to 9 (very). Their responses were divided into low (1-3), intermediate (4-6) and high (7- -9) ratings (see table 1).

Participants were asked open-ended questions to explore in more detail what they found useful about these workshops, and how they could be improved. Representative examples of GP trainees' responses are shown below.

1. What aspects of the sessions did you find most useful for encouraging you towards greater reflection? 
Table 1 Feedback on photography workshops

\begin{tabular}{|c|c|c|c|}
\hline Question & Low value $(\%)$ & Intermediate (\%) & High value $(\%$ \\
\hline How interesting did you find the photography workshops? & 0 & 14 & 86 \\
\hline Overall, how useful did you find the photography workshops for personal development? & 0 & 14 & 86 \\
\hline Overall, how useful did you find the photography workshops for training to be a general practitioner? & 0 & 14 & 86 \\
\hline To what extent do you think the photography workshops assisted you in developing your skills in reflection? & 0 & 0 & 100 \\
\hline To what extent do you think the photography workshops assisted you in understanding yourself? & 0 & 14 & 86 \\
\hline
\end{tabular}

- The way that we were encouraged to initially take lots of photographs without too much thought has enhanced my approach to reflection-noting down events I find interesting but have not yet understood why

- Talking through the photos as a group and realising differences in what we saw in the same photo.

- Looking at themes in my photos helped me reflect on myself.

- Encouraged me to be more mindful and take note of my surrounding.

- Thinking about how we view the world around us and how we interpret things visually.

2. What aspects of the sessions did you find most useful for encouraging you towards increased self-awareness?

- Time to take photos, look back on them, reflect as a group and then look at them again ourselves.

- Allowing yourself to not overthink composing a photograph and listening to the 'inner' self.

- It has encouraged me to take more time to listen to my own thoughts and self-doubts and try to challenge them.

- Identifying recurring themes in photos.

3. In your view, how might the sessions have been improved to assist you towards greater reflection and/or self-awareness?

- More time to discuss photos as a group as this is such an abstract idea to me.

- Perhaps discussing the self-reflections at the final session.

4. In your view, how might the assigned task have been improved to assist you towards greater reflection and/or self-awareness?

- Focus more on fewer photos in more depth rather than more in less detail.

- Contrast own pictures with being given other pictures to comment on.

- Some focus on the written task in the previous session, or practice a shorter reflective piece before.

- Seeing an example from someone else.

As this was the first time we had run this workshop, we were also very interested in the participants' general observations, comments and feedback. Responses received included

- Unusual approach and refreshing.

- Overall really enjoyable experience. This has been really useful to be self-aware at this point in my training. This has helped me be more honest with myself about my career.

- This was really enjoyable, particularly challenging ourselves to think in creative and abstract ways, which was unfamiliar to me.

\section{CONCLUSION}

This highly innovative approach to medical education was a collaboration between a photographic artist and the Dorset GP Training scheme. It formed a compulsory part of the GP education programme. This compulsory aspect is important because arts-based teaching can otherwise be regarded as 'ornamental" 2 ; a voluntary add-on for those who have a particular interest or inclination towards the arts perpetuates the idea that it is somehow both less important and less valuable. ${ }^{23}$ A recent UK All-Party Parliamentary Group report on the role of arts in health and well-being emphasised the need for a cultural shift and 'an informed and open-minded willingness to accept that the arts can make a significant contribution to addressing a number of the pressing issues faced by our health and social care systems'. ${ }^{13}$ This cultural shift can start by giving junior health professionals the opportunity to experience the benefits of the arts themselves, through dedicated modules on training curricula.

These photography workshops gave GP trainees space (both physically and educationally), away from their usual training, to explore important issues that impact on their clinical decision-making and professional development. A qualitative analysis of the photographs and reflective texts pointed to the salience of training as a journey and the GP trainees' need for equilibrium amidst contradiction. Recent studies have called for the need to explore metaphor and the subtlety of language ${ }^{24}$ and the conspicuous absence of emotion in medical education discourse. ${ }^{25}$ The project took place during the weeks which saw the first 'all-out' doctors strike in the history of the National Health Service. Perhaps as a consequence of the emotionally safe and mutually supportive group dynamic that developed between GP trainees in sharing their reactions to and interpretations of their photographs, the topics of morale, the recruitment crisis within general practice and professional resilience were all openly discussed.

The GP trainees reported that they found photography to be a 'refreshing', 'enjoyable' and 'really useful' means to develop their self-insight as well as their ability, and inclination, to reflect. Despite their scientific backgrounds and usual focus on objectivity, empirical knowledge and evidence based guidelines, they found art to be an acceptable and accessible means to personal and professional development. The GP trainees did not have any prior specialist interest in photography but they valued the educational approach and found it beneficial in identifying issues that impacted on their work and their lives. We suggest that photography is well suited to enhancing reflective capacity, and our study demonstrates that the approach is perceived to be enjoyable, useful and valid for doctors. The arts can enhance the professional development of doctors and should be more fully integrated into training curricula. ${ }^{13}$

Acknowledgements The authors wish to express their very sincere appreciation to the GP trainees who took part in this series of workshops and who graciously gave permission to reproduce their photographs and the excerpts from their selfreflective texts.

Contributors $E F, R, A B$ and $C W$ were involved in the planning and leadership of this work. $E F, A B$ and $R$ led on the development and delivery of the material in the workshops. EF, JP-H and R led on the evaluation. All authors contributed to the literature review and preparation of this manuscript.

Competing interests None declared. 
Ethics approval Ethical approval for the research component of this work was obtained from Bournemouth University's Science, Technology and Health Research Ethics panel.

Provenance and peer review Not commissioned; externally peer reviewed.

(c) Article author(s) (or their employer(s) unless otherwise stated in the text of the article) 2018. All rights reserved. No commercial use is permitted unless otherwise expressly granted.

\section{REFERENCES}

1 Wald HS, Haramati A, Bachner YG, et al. Promoting resiliency for interprofessional faculty and senior medical students: outcomes of a workshop using mind-body medicine and interactive reflective writing. Med Teach 2016;38:525-8.

2 Royal College of General Practitioners. (UK) Online GP Curriculum. http://www.rcgp. org.uk/training-exams/gp-curriculum-overview/online-curriculum/1-being-a-gp/corecapabilities-and-competences.aspx

3 Karkabi K, Wald HS, Cohen Castel 0 . The use of abstract paintings and narratives to foster reflective capacity in medical educators: a multinational faculty development workshop. Med Humanit 2014;40:44-8.

4 Wald HS, Borkan JM, Taylor JS, et al. Fostering and evaluating reflective capacity in medical education: developing the reflect rubric for assessing reflective writing. Acad Med 2012;87:41-50.

5 Tsao P, Yu CH. "There's no billing code for empathy" - animated comics remind medical students of empathy: a qualitative study. BMC Med Educ 2016;16:204.

6 Ogston-Tuck S, Baume K, Clarke C, et al. Understanding the patient experience through the power of film: a mixed method qualitative research study. Nurse Educ Today 2016;46:69-74.

7 Shapiro J, Hunt L. All the world's a stage: the use of theatrical performance in medical education. Med Educ 2003;37:922-7.

8 Elder NC, Tobias B, Lucero-Criswell A, et al. The art of observation: impact of a family medicine and art museum partnership on student education. Fam Med 2006;38:393-8

9 Karkabi K, Cohen Castel 0 . Teaching reflective competence in medical education using paintings. Med Humanit 2011;37:58-9.
10 Barber S, Moreno-Leguizamon CJ. Can narrative medicine education contribute to the delivery of compassionate care? A review of the literature. Med Humanit 2017;43:199-203.

11 Ousager J, Johannessen $\mathrm{H}$. Humanities in undergraduate medical education: a literature review. Acad Med 2010;85:988-98.

12 Perry M, Maffulli N, Willson S, et al. The effectiveness of arts-based interventions in medical education: a literature review. Med Educ 2011;45:141-8.

13 NHS England. Creative health: the arts for health and wellbeing. All-party parliamentary group on arts, health and wellbeing inquiry report, 2017.

14 Brand G, McMurray A. Reflection on photographs: exploring first-year nursing students' perceptions of older adults. J Gerontol Nurs 2009;35:30-7.

15 Wald HS, Norman DR, Walker J. Reflection through the arts: focus on photography to foster reflection in a health care context. Living beyond - an interactive photographic exhibit. Reflective Practice 2010;11:545-63.

16 Brand G, Miller K, Saunders R, et al. Expanding the caring lens: nursing and medical students reflecting on images of older people. Gerontol Geriatr Educ 2016;37:167-84.

17 Rutherford. The Shadow of the Photographer: Using photographic snapshots in our search for meaning and fulfilment. Canadian Art Therapy Association (CATA) Journal 2002;15:14-32.

18 Sacks 0. The man who mistook his wife for a hat. Br J Psychiatry 1995;166:130-1.

19 Jung CG. Modern man in search of a soul. Psychology Press, 2001.

20 Erwitt E. Famous quotes from photographer Elliott Erwitt. https://www.brainyquote. com/quotes/elliott_erwitt_141210 (accessed 14 Jan 2017).

21 Boyatzis RE. Transforming qualitative information: thematic analysis and code development. Sage, 1998.

22 Peterkin A. Curating the medical humanities curriculum: twelve tips. Med Humanit 2016:42:147-8.

23 Thresher K, Boreham L, Dennison L, et al. Exploring art with foundation doctors: reflecting on clinical experience. Educ Prim Care 2013;24:212-5.

24 Loftus S. Pain and its metaphors: a dialogical approach. J Med Humanit 2011;32:213-30.

25 McNaughton N. Discourse(s) of emotion within medical education: the ever-present absence. Med Educ 2013;47:71-9. 


\section{Using photography to enhance GP trainees' reflective practice and professional development}

Rutherford, Emer Forde, Jacqueline Priego-Hernandez, Aurelia Butcher and Clare Wedderburn

Med Humanities published online February 8, 2018

Updated information and services can be found at:

http://mh.bmj.com/content/early/2018/02/08/medhum-2017-011203

\section{These include:}

References This article cites 20 articles, 5 of which you can access for free at: http://mh.bmj.com/content/early/2018/02/08/medhum-2017-011203\#re f-list-1

Email alerting Receive free email alerts when new articles cite this article. Sign up in the service box at the top right corner of the online article.

Topic Articles on similar topics can be found in the following collections Collections

Medical education (4)

\section{Notes}

To request permissions go to:

http://group.bmj.com/group/rights-licensing/permissions

To order reprints go to:

http://journals.bmj.com/cgi/reprintform

To subscribe to BMJ go to:

http://group.bmj.com/subscribe/ 